\title{
Overview of the work in Latin America on erosion and sediment dynamics
}

\author{
Cristiano Poleto • Jorge Enoch Furquim Werneck Lima • \\ José Carlos de Araújo
}

Received: 23 April 2014 / Accepted: 25 April 2014 / Published online: 8 May 2014

(C) Springer-Verlag Berlin Heidelberg 2014

\section{Introduction}

Recently, hydrosedimentological investigations have gained increasing attention from society due to a broader understanding and appreciation of the socioeconomic and environmental impacts of erosion and sedimentation processes. In Latin America, where much of the produced electricity comes from hydroelectric power plants and where land use changes at a considerable rate, a deeper understanding of sediment-related processes is important.

Other driving forces that have boosted hydrosedimentological research in the Latin American continent are the increasing international demand for food, which has led to the expansion of agricultural frontiers; mining activities; the unplanned occupation of erosion-prone urban sites by vulnerable families in large cities; the attempts to further exploit new waterways; the management of sediment in harbors; as well as environmental issues associated with aquatic systems.

A clear evidence of the societal-including the governmental sectors - perception of sediment-associated issues and questions can be demonstrated by the new regulation published in 2010 by two Brazilian agencies: National Water Agency (ANA) and National Energy Agency (ANEEL).

\footnotetext{
C. Poleto $(\bowtie)$

Hydraulic Research Institute, Federal University of Rio Grande do Sul, Porto Alegre, RS CEP 91501970, Brazil e-mail: cristiano_poleto@hotmail.com

J. E. F. W. Lima

Embrapa Cerrados, Empresa Brasileira de Pesquisa

Agropecuária (Embrapa), Planaltina, DF 73310-970, Brazil

e-mail: jorge.werneck-lima@embrapa.br

J. C. de Araújo

Department of Agricultural Engineering, Federal University of

Ceará, Campus do Pici, Fortaleza, CE 60356-000, Brazil

e-mail: jcaraujo@ufc.br
}

According to the new regulation, the companies that own hydroelectric power plants are obliged to monitor not only water but also sediment fluxes in reservoirs. This initiative generated a large demand for experts in the area and induced investments in research regarding sediment dynamics in fluvial systems, focusing on the socioeconomic sustainability of anthropogenic interventions.

Furthermore, the recent construction of hydroelectric power plants in the Amazon region, which receives a considerable input from the Andes, also demands expert knowledge regarding sediment fluxes and integrated water-sediment management. In regions where water conflicts are already a reality, the number of multipurpose surface reservoirs expands at a high rate, generating complex networks, which strongly intervene in sediment and water flows. Considering that the siltation of strategic water reservoirs lessens water availability, a more thorough understanding of sediment sources and dynamics is of paramount interest for water-scarce regions in the continent.

The advance of agricultural frontiers and the construction of dams in the Upper Paraguay River basin are, for instance, generating severe changes in the natural sediment fluxes, which lead to discussions on the long-term impact on the Pantanal Biome. The $150,000-\mathrm{km}^{2}$ biome is one of the largest wetland systems on earth. Another Latin American region that raises international concern related to sediment fluxes is the area that drains its waters into the Panama Canal. Due to its economic significance, the constant engineering works for the expansion of the canal and its dredging have been a relevant driving force for advances in terms of erosion and sedimentation studies.

The great extent of Latin America - with a broad spectrum of climate, relief, soil, and land use - generates a favorable environment for diversified research initiatives in sedimentology. This is an overview related to sediment erosion, transport, and sedimentation in present Latin America. It clearly encompasses great possibilities for scientific and technological advances in the near future. 


\section{Studies in Latin America}

This special issue presents 12 papers about recent studies in Latin America related to the acquisition of data, information, and knowledge necessary for an adequate coexistence of humankind with the problems that may occur as a result of erosion and sedimentation processes. The papers deal with topics such as monitoring and modeling of erosion and sedimentation processes, model application to support integrated land and water resources management, as well as issues related to the chemical characteristics of the sediments and their impacts on water quality.

Several investigations focused on the qualitative aspects of sediments, as well as on the interaction between pollutants transported by sediments and aquatic ecosystems. The application of such investigations to urban watersheds and water resource management prevails, due to their contamination potential. This is particularly true in Latin America, where sanitation systems are still not satisfactorily implemented. The importance of urban sediments as pollutant transport media is associated with their ability to absorb constituents, such as heavy metals. Martinez and Poleto (2014) concluded that zinc, cadmium, and nickel concentrations in sediments of urban watersheds are high and, according to the geoaccumulation index, contamination was considered as moderate.

Some sediment analyses also showed the presence of pharmaceutical and personal care products (PPCPs). According to Beretta et al. (2014), all PPCPs found in the samples are in the order of magnitude of parts per billion of dry sediment. All sediment samples presented PPCPs, and their respective concentrations were statistically significant in the clay fraction of the samples. The information drawn from these investigations should help decision makers to design strategies that minimize pollution and its impacts on urban water bodies.

Research in agricultural areas is mainly focused on the economic implications of erosion. The studies accomplished by Didoné et al. (2014) quantified liquid and solid discharges in two mesoscale agricultural watersheds (800 and $2,000 \mathrm{~km}^{2}$ ), which differ in terms of soil and water conservation status. The monitoring of suspended sediment concentration in the study areas, based on rating curves, identified very high sediment yields in both catchments, indicating intense erosive processes and the impact of agriculture on water resources.

Rodrigues et al. (2014) investigated the effects of eucalyptus crops on hydrosedimentological processes in two nested watersheds. For this purpose, the authors used the Limburg Soil Erosion Model (LISEM), which adequately reproduced the peak discharges and total runoff of events, but failed to adequately reproduce the hydrograph shapes.

Medeiros and de Araújo (2014) attempted to understand the variability of erosive processes as a function of rainfall characteristics (mainly their temporal variability). The authors monitored rainfall, as well as water and sediment fluxes, in a semiarid watershed from 2004 to 2011 . The results showed that a large fraction of the annual erodibility was caused by a few very intense events, several of which had durations up to $1 \mathrm{~h}$.

The previously mentioned papers demonstrated the impact of sediment fluxes on water resources and their considerable consequences on hydroelectric power plant operations as well as on water supply policies. Accordingly, several research groups in Latin America are studying, monitoring, and developing new techniques to understand problems associated with reservoir siltation. In this context, Estigoni et al. (2014) analyzed the accuracy of 20 bathymetric surveys using the single beam digital elevation model proposed by the Brazilian Water Agency, ANA, and compared the results with that of a very detailed terrain survey. The authors concluded that the method - as proposed by ANA - has not always yielded results with the desired accuracy, which showed the need for further investigation, especially concerning the density of measurements.

As far as suspended sediment discharge monitoring is concerned, Merten et al. (2014) assessed the sensitivity of sediment concentration and particle size over three different turbidity sensors. The position of the instrument in relation to the light incidence was also evaluated. The results proved the relevance of in situ calibration to the quality of turbidimeter signals.

Xavier et al. (2014) calibrated acoustic Doppler equipment in a laboratory using the acoustic intensity scattering and the signal-to-noise ratio to assess the suspended sediment concentration. The results demonstrated that, despite the need for advances in this sort of investigation, there was a clear indication that the acoustic Doppler technique is well-suited for evaluating suspended sediment concentration.

De Barros et al. (2014) assessed the applicability of the LISEM model to precipitation events in a small rural watershed, focusing on erosion and sedimentation processes. The authors discussed the physical and hydrological characteristics of the soils and their correct representation in the parameterization process in order to achieve a valid model representation.

De Farias and Santos (2014) developed and assessed selforganizing maps using the neural network technique to estimate the sediment yield in semiarid basins based on climatic and runoff data. The results proved to be satisfactory and better than those generated by the multivariate linear modeling of the monitored data.

Michel et al. (2014) used information generated for integrated land and water resource management to assess the performance of two hillslope stability models: SHALSTAB and SINMAP. Both models consider hydrological, pedological, and topographical variables in their formulation. The results showed that SHALSTAB was able to model landslides more efficiently, whereas SINMAP prevailed when the application was basin planning (for example, mapping risk zoning and urban expansion). 
Lima et al. (2014) applied the Universal Soil Loss Equation (USLE), coupled with a geographic information system (GIS), to aid implementing economic mechanisms in land management, such as the Payment for Environmental Services (PES). The authors analyzed a small rural watershed located in the Cerrado Biome and investigated the potential implementation of an erosion control program with prioritized actions. They also indicated which stakeholders should pay for, and which ones should be paid by, environmental services.

\section{Conclusion}

The manuscripts presented in this special issue show an expansion of sampling techniques and a clear tendency for the continuous development of mathematical modeling, with an emphasis on sediment generation and sediment yield processes. Notable advances in sediment-related knowledge in Latin America during the last decades were depicted. Further progress is expected in the coming decades not only due to the better socioeconomic conditions on the continent but also due to the increasing number of experts in sediment monitoring, management, and investigation.

\section{References}

Beretta M, Britto V, Tavares TM, da Silva SMT, Pletsch AL (2014) Occurrence of pharmaceutical and personal care products (PPCPs) in marine sediments in the Todos os Santos Bay and the north coast of Salvador, Bahia, Brazil. doi:10.1007/s11368-014-0884-6, this issue de Barros CAP, Minella JPG, Dalbianco L, Ramon R (2014) Description of hydrological and erosion processes determined by applying the LISEM model in a rural catchment in southern Brazil. doi:10.1007/ s11368-014-0903-7, this issue

de Farias CAS, Santos CAG (2014) The use of Kohonen neural networks for runoff-erosion modeling. doi:10.1007/s11368-013-0841-9, this issue

Didoné EJ, Minella JPG, Reichert JM, Merten GH, Dalbianco L, de Barros CAP, Ramon R (2014) Impact of no tillage agricultural systems on sediment yield in two large catchments in Southern Brazil. doi:10.1007/s11368-013-0844-6, this issue

Estigoni MV, Matos AJS, Mauad FF (2014) Assessment of the accuracy of different standard methods for determining reservoir capacity and sedimentation. doi:10.1007/s11368-013-0816-x, this issue

Lima JEFW, Lopes WTA, Aqino FG, Oliveira-Filho EC, Sano EE, di Silva FDM (2014) Assessing the use of erosion modeling to support payment for environmental services programs. doi:10.1007/s11368013-0821-0, this issue

Martinez LLG, Poleto C (2014) Assessment of diffuse pollution associated with metals in urban sediments using the geoaccumulation index $\left(\mathrm{I}_{\text {geo }}\right)$. doi:10.1007/s11368-014-0871-y, this issue

Medeiros PHA, de Araújo JC (2014) Temporal variability of rainfall in a semiarid environment in Brazil and its effect on sediment transport processes. doi:10.1007/s11368-013-0809-9, this issue

Merten GH, Capel PD, Minella JPG (2014) Effects of suspended sediment concentration and grain size on three optical turbidity sensors. doi:10.1007/s11368-013-0813-0, this issue

Michel GP, Kobiyama M, Goerl RF (2014) Comparative analysis of SHALSTAB and SINMAP for landslide susceptibility mapping in the Cunha River basin, southern Brazil. doi:10.1007/s11368-0140886-4, this issue

Rodrigues MF, Reichert JM, Minella JPG, Dalbianco L, Ludwig RL, Ramon R (2014) Hydrosedimentology of nested subtropical watersheds with native and eucalyptus forests. doi:10.1007/s11368-0140885-5, this issue

Xavier BC, Silva IO, Guimarães LG, Gallo MN, Ribeiro CP, Figueiredo Jr AG (2014) Estimation of suspended sediment concentration by acoustic scattering: an experimental and theoretical analysis for spherical particles. doi:10.1007/s11368-014-0905-5, this issue 